\title{
Study and therapeutic progress on spinal cord perimedullary arteriovenous fistulas (Review)
}

\author{
TIEFENG $\mathrm{JI}^{1}$, YUNBAO GUO ${ }^{2}$, LEI SHI ${ }^{2}$ and $\mathrm{JINLU}^{\mathrm{Y}} \mathrm{U}^{2}$ \\ Departments of ${ }^{1}$ Radiology and ${ }^{2}$ Neurosurgery, The First Hospital of Jilin University, Changchun, Jilin 130021, P.R. China
}

Received July 10, 2017; Accepted July 25, 2017

DOI: $10.3892 /$ br.2017.951

\begin{abstract}
Spinal cord perimedullary arteriovenous fistulas (PMAVFs) are rare and belong to type IV spinal cord arteriovenous malformations (AVMs). Little is known regarding the treatment and prognosis of spinal cord PMAVFs. In the present study the relevant literature from PubMed was reviewed, and it was found that these fistulas can occur at all ages but are more common in children. In children, most spinal cord PMAVFs are large and with high flow, begin with bleeding and are frequently associated with hereditary hemorrhagic telangiectasia. However, in adults, most spinal cord PMAVFs are small and with low flow and begin with progressive spinal cord dysfunction. The early diagnosis of spinal cord PMAVFs is generally difficult, and symptoms can be very severe at the time of diagnosis. Digital subtraction angiography remains the gold standard; however, computed tomography angiography and magnetic resonance angiography are also promising. Spinal cord PMAVFs can be treated by endovascular embolization, surgical removal or a combination of the two methods. Most spinal cord PMAVFs show good outcomes after the appropriate treatment, and the prognosis is primarily associated with the blood flow of the PMAVF. For high-flow spinal cord PMAVFs, endovascular embolization is more effective and can lead to a good outcome; however, for low-flow spinal cord PMAVFs, surgical removal or the combination with endovascular embolization is the optimal choice. The prognosis for low-flow types is slightly worse than for high-flow spinal cord PMAVFs in children, but the outcome is acceptable.
\end{abstract}

\section{Contents}

1. Introduction

2. Natural history of PMAVFs

Correspondence to: Dr Jinlu Yu, Department of Neurosurgery, The First Hospital of Jilin University, 71 Xinmin Avenue, Changchun, Jilin 130021, P.R. China

E-mail: jinluyu@hotmail.com

Key words: spinal cord, perimedullary arteriovenous fistula, treatment, progress
3. Angioarchitecture and classification of spinal cord PMAVFs

4. Clinical characteristics of spinal cord PMAVFs

5. Imaging manifestation of spinal cord PMAVFs

6. Treatment of spinal cord PMAVFs

7. Therapeutic outcome of spinal cord PMAVFs

8. Complications of spinal cord PMAVF treatment

9. Conclusion

\section{Introduction}

Spinal cord perimedullary arteriovenous fistulas (PMAVFs) were first described in 1977 by Djindjian et al (1). These fistulas are located on the pial surface of the spinal cord at the transition from the spinal artery to the medullary vein, without an intervening nidus of abnormal vessels (2). The exact etiology of spinal cord PMAVFs is unclear as their occurrence may be associated with congenital factors or secondary to an iatrogenic injury that occurs during epidural anesthesia or spinal canal surgery (3). There have also been studies of spinal cord PMAVFs caused by stab wounds $(4,5)$. The natural history of spinal cord PMAVFs is unclear, but it has been suggested that asymptomatic PMAVFs are rare. Once PMAVFs appear, rupture, bleeding or progressive spinal cord dysfunction occurs (6). Due to our currently limited understanding of spinal cord PMAVFs, many cases are initially misdiagnosed as other diseases, and the opportunity for optimal treatment is thereby lost. At present, the treatment of PMAVFs primarily includes interventional embolization and surgical treatment or a combination of the two methods, and a variety of factors may affect the prognosis (7). As there are many uncertainties regarding spinal cord PMAVFs, the present study considers studies found from PubMed to review the status of the current research and the treatment of spinal cord PMAVFs.

\section{Natural history of PMAVFs}

At present, the natural history of spinal cord PMAVFs is not completely clear (8). When PMAVFs occur, they typically cause clinical symptoms; asymptomatic cases are rare. In 2013, Gross and Du collected data for 213 patients and 28 studies. In these patients, only $1 \%$ of spinal cord PMAVFs were incidental and asymptomatic without bleeding, and the annual hemorrhage rate was $2.5 \%$, increasing to $5.6 \%$ for hemorrhagic fistulas. Patient sex, fistula location and fistula 
subclass were not significant risk factors for hemorrhage (9). Once spinal cord PMAVFs occur, the chance of self-healing is minimal. However, it has been shown that the draining veins of spinal cord PMAVFs can spontaneously heal by forming a thrombosis. For example, in 2012, Takai and Usui reported a case of spinal cord PMAVF that was examined after clinical symptoms occurred. Those authors found that the veins of the PMAVF had already spontaneously formed a thrombosis (10). In addition, there are studies that describe the occlusion of PMAVFs after spinal cord angiography. For example, in 2004, Aydin et al reported a case of a 29-year-old female whose symptoms gradually improved within 1 week after angiography, and a second angiography examination of this patient showed that the PMAVF had disappeared. Slowing of the shunt flow in the PMAVF caused by selective catheterization of the feeding artery and the thrombogenic effect of the contrast media may result in spinal cord PMAVF thrombosis (11).

\section{Angioarchitecture and classification of spinal cord PMAVFs}

Angioarchitecture of PMAVFs. Spinal cord PMAVFs obtain their blood supply from the ventral and/or dorsal spinal arteries. When the fistulas are ventral and directly fed by the anterior spinal artery, they are subpial in location, whereas those fed by the posterior spinal arteries, they are subarachnoid. However, because of the free communications between the anterior and posterolateral arterial supply to the spinal cord via transmedullary or circumferential anastomosis, the sole contribution of the radiculo-pial arteries without anterior spinal artery involvement is unusual (12-15). The venous drainage of spinal cord PMAVFs includes the perimedullary veins over the anterior and posterior surfaces of the spinal cord, often extending over multiple levels, with pial venous reflux and congestion being the most frequently encountered features (16).

Similar to aneurysms that are associated with brain arteriovenous malformations (AVMs), PMAVFs can also be combined with aneurysms on feeding arteries caused by increased hemodynamic pressure or congenital factors; however, this situation is very rare (17). The first case was reported in 2005 by Ohmori et al in which the PMAVF was located on the thorax and the aneurysm was located on the feeding anterior spinal artery. In this case, the aneurysm was resected (18). Anderer et al also reported 1 case of thoracic PMAVF in 2008 in which a patient had two aneurysms on the feeding arteries (19). Apart from the aneurysms on the feeding arteries, some aneurysms of PMAVFs may also be located at the fistula. For example, of the 22 cases reported by Endo et al in 2014, nine had combined aneurysms at the fistula (20).

Classification of PMAVFs. There are many classifications for spinal cord PMAVFs, most using the feeding arteries and the angioarchitecture as the basis for classification $(21,22)$. The most popular classification was proposed in 2002 by Spetzler et al, improved the Merland-Cognard classification in the following categories: i) Type A fistulas are characterized by a single feeding artery with low flow through the arteriovenous shunt and moderate venous enlargement; ii) type B fistulas are intermediate in size, often have multiple feeding arteries and show more marked venous enlargement than type $\mathrm{A}$; and iii) type $\mathrm{C}$ fistulas are the largest of these types of fistulas and these are multipediculated, with high-blood flow and enlarged, tortuous draining veins (23). In this classification system, most PMAVFs are type A micro-PMAVFs, accounting for approximately $75 \%$ of lesions by contrast, macro-PMAVFs are relatively rare, accounting for approximately $25 \%$ of cases $(16,24,25)$. Giant PMAVFs are included among macro-PMAVFs and are more difficult to treat (26).

Spinal cord PMAVFs can occur individually, but multiple PMAVFs can also occur. Multiple spinal cord PMAVFs may be associated with certain syndromes, such as Klippel-Trenaunay syndrome (27) and Parkes-Weber (PW) syndrome (28). In addition, spinal cord PMAVFs can occur together with other spinal vascular diseases at the same site (29,30). For example, in 2015, Shin et al reported a case of spinal AVF combined with arteriovenous malformation (31). In another example, Gekka et al reported the case of a 37-year-old male with simultaneous intramedullary AVMs and PMAVFs at the C3 to C5 level (32). In addition, spinal cord PMAVFs can be classified into ventral and dorsal types (33). This classification has clinical significance; for ventral PMAVFs, a rear-approach surgery can be used, whereas front-approach surgery can be considered for ventral PMAVFs.

\section{Clinical characteristics of spinal cord PMAVFs}

Age, sex and site. Spinal cord PMAVFs are most common early in life, and previous studies have shown that there is no gross sex difference $(21,34)$. However, in 2013, Gross and Du summarized 213 cases reported from 28 studies and found that patients with type A PMAVFs were significantly older (mean age, 46.9 years) and primarily male (68\% male). By contrast, patients with type C PMAVFs were significantly younger (mean age, 18.7 years) and showed no sex bias (9). It has recently been reported that the incidence of PMAVFs in children accounts for $1 / 3$ of the incidence in the population and includes almost all macro-PMAVFs, while the remaining $2 / 3$ occur in adults, and these are primarily micro-PMAVFs (16). There is some degree of uniformity in the PMAVF site, with the preferred site being in the thoracolumbar region and neck localization being less common (34). For example, of the 213 cases PMAVFs studied by Gross and Du, 37 of the 183 treated cases were in the neck, 59 were in the thorax and 87 were in the lumbar spine (9).

Clinical manifestation. Spinal cord PMAVFs are difficult to diagnose, and most are misdiagnosed as other diseases at their onset. Therefore, there is a certain incubation period. In a 2010 study of 32 cases, Antonietti et al found that the average time to diagnosis was 17 months for all 32 patients. For the 20 patients with chronic symptoms, the average time to diagnosis was 24.6 months. For the 12 patients with acute symptoms, the average time to diagnosis was 0.5 months (21). When spinal cord PMAVFs produce clinical symptoms, $93 \%$ of patients presented with neurologic deficits and $36 \%$ with hemorrhage. The neurologic deficit can be exacerbated by compression, such as a lumbar disc herniation, which can distort the angioarchitecture of the draining vein, thereby worsening the severity of perimedullary venous hypertension (35). 
Bleeding primarily occurred in high-flow PMAVFs, such as hematomyelia and subarachnoid hemorrhage (SAH). High-flow PMAVFs are more often associated with syndromes such as Cobb syndrome, hereditary hemorrhagic telangiectasia (HHT), and they are more common in children. Neurologic deficits primarily occur in low-flow PMAVFs, which frequently have a long history of progressive myelopathy and are more common in adults $(16,36)$. The SAH may also be associated with the PMAVF location. For example, in a 2014 study, Endo et al reported 22 cases of cervical cord PMAVFs, of which 17 showed SAH, which may be associated with the abundant blood supply of the cervical spinal cord (20). Rarely, thoracolumbar and even conus PMAVFs can exhibit intracranial SAH, requiring more attention (37-39).

Combination with rare diseases. Spinal cord PMAVFs are occasionally found in combination with HHT, Cobb syndrome or Klippel-Trenaunay-Weber syndrome, the incidence of such cases being approximately $29 \%$. In addition, these types of PMAVFs may occur together with other rare diseases and even tumors $(3,9,28,40)$. In children, there is a high association of PMAVFs with HHT; therefore, HHT should be considered whenever a PMAVF is encountered in the spinal cord. However, none of the adult PMAVF patients had HHT $(8,41)$. For example, of the 32 cases reported by Rodesch et al in 2005, 10 were children and 5 of these occurred in combination with HHT. By contrast, none of the 22 adult cases were present in patients with HHT syndrome (16). PMAVFs combined with neurofibromatosis have also been reported. For example, in 2007, Saito et al reported a 62-year-old female who had an intercostal PMAVF at the T10-12 position, which was simultaneously combined with neurofibromatosis (42). In a study on split cord malformation, Vitarbo et al reported a 62-year-old female with an L2 level PMAVF combined with split cord malformation (43). PMAVFs can evidently occur in combination with various deformities, suggesting that the occurrence of PMAVFs is associated with congenital factors. In addition, PMAVF may be combined with tumors. For instance, in 2008, Hung and Chiang reported a case of PMAVF concomitant with a cauda equina schwannoma (44). There is also a study of PMAVFs in association with familial pulmonary vascular malformations (45).

\section{Imaging manifestation of spinal cord PMAVFs}

Magnetic resonance angiography (MRA) and magnetic resonance imaging (MRI). In MRA and MRI, ectasia of the vein typically marks the transition point between the artery and the vein. PMAVFs typically demonstrate an enhanced dilated perimedullary vein or an ectatic venous pouch in combination with an enlarged spinal artery and no AVM nidus (46). For macro-PMAVFs, the venous ectasia may be so large that it compresses the cord and contributes to cord dysfunction, as indicated by a focal hyperintensity on T2-WI compared to the venous ectasia. For micro-PMAVFs, MRI and MRA may show a tangle of tubular vessels that is superficial to the cord. These flow-void structures are primarily veins that are larger than arterial feeders (47). Unsrisong et al used MRA to examine PMAVFs, performing the fast 3D contrast-enhanced MRA technique via manual contrast injection. Of 5 cases of
PMAVFs, 4 were clearly visible; therefore, this method may be more promising for clinical application (48). In another example, Toossi et al reported that in a study where two blinded board-certified radiologists reviewed 36 PMAVF cases, MRI was sufficiently sensitive to correctly determine the primary diagnosis in $94 \%$ of cases. Those authors also reported that spinal angiography is mandatory in the presence of both T2 hyperintensity and flow voids but may be unnecessary if both of these findings are absent (49).

Computed tomography angiography (CTA). CT has developed rapidly in recent years, and CT imaging quality has continuously improved. More clinical expertise has accumulated in the diagnosis of PMAVFs by CTA, making it a powerful tool for diagnosis. In a 1999 study, Hasegawa et al reported 2 cases of PMAVFs. Authors of that study used CTA, which clearly showed the feeding arteries, fistulas and draining vein (50). Furthermore, Yamaguchi et al used CTA to examine a 75-year-old female with a PMAVF at the L3 level of the filum terminale. Multi-detector-row CTA revealed the broad range of the vascular lesion and the anterior spinal artery as a feeder. The fistulous point and the draining vein were observed on the multiplanar reformatted (MPR) image (51). 4D-CTA using 320-row area detector CT on spinal arteriovenous fistulas may have more prospects for clinical applications (52).

Digital subtraction angiography (DSA). Spinal angiography with CT and contrast-enhanced MRA may be able to clearly show the extent of spinal vascular malformations, feeding arteries and fistulas. These methods are safe, non-invasive and rapid, shortening the time required for DSA diagnosis and treatment (53). However, DSA remains the gold standard for the diagnosis of PMAVFs because CTA and MRA often fail to provide the important data necessary for the characterization of the lesion, such as information on multiplicity, potential metameric nature, architectural features and precise localization. In some cases, 3D rotational spinal angiography may be required $(54,55)$. However, DSA is not always a panacea; in DSA, slow-flow PMAVFs may be difficult to recognize because the feeding radiculomedullary artery is only slightly enlarged and the shunt flow is slow. In this case, a longer venous phase is needed. Therefore, Sorte et al suggested that an extension of the venous phase is needed for observation (56).

\section{Treatment of spinal cord PMAVFs}

Available spinal cord PMVAF treatments include surgery, endovascular embolization and a combination of the two methods. Regardless of the method used, the fistula must be completely removed or blocked during treatment. Occasionally, postoperative problems can arise due to multiple fistulous connections that cannot all be corrected, a failure of the embolic agent or the surgical clips/ligation to completely block flow and/or a challenging location of the fistula. Such residual fistulas may cause a patient's symptoms to continue or gradually worsen, and treatment should be continued as early as possible (57).

Surgical removal. For type A and some type B PMAVFs, endovascular techniques are difficult because even with the thinnest 
microcatheter; some feeding arteries are simply too small to permit ideal catheter tip positioning for super-selective fistula embolization. In this case, surgical excision is often preferred. For example, the interventional treatments of 20 PMAVF patients described by Phadke et al (most with types A or B PMAVFs) were generally unsuccessful because the feeding arteries were too thin or tortuous; however, surgical treatment was successful (58). The key purpose of surgical treatment for spinal cord PMAVFs is to locate the fistula orifice and to remove or close it. Although surgical methods are effective, it can still be difficult to locate the fistula, for which intraoperative near-infrared indocyanine green (ICG) videoangiography is an effective method. ICG reveals the transition from the spinal artery to the medullary vein and is very useful in removing or closing the fistula orifice $(59,60)$. When intraoperative ICG cannot be performed, intraoperative ultrasound is also a good option $(61,62)$. Of course, intraoperative DSA assistance is the best choice $(32,63)$. Thus, intraoperative monitoring examinations are necessary for the surgical removal of PMAVFs.

For the surgery itself, the therapeutic approach should be chosen according to the location of the PMAVF. When the main body is on the dorsal side of the spinal cord, the rear approach by way of cutting the lamina can be used. However, some PMAVFs are located in front of the spinal cord, and because the range of motion of the spinal cord is limited, it is difficult to reach the front via the rear approach; in this case, the anterior approach should be attempted. For example, Hida et al reported that five cervical PMAVF patients underwent corpectomy via an anterior approach with satisfactory results (64). In another study by Gekka et al, direct surgery was performed via an anterior approach using corpectomy to treat a 37-year-old male. This case confirmed that the anterior approach is feasible (32). Of the 22 patients studied in 2014 by Endo et al, 21 underwent open surgery; an anterior approach with corpectomy was selected for 2 patients (20). Therefore, for PMAVFs on the ventral side of the spinal cord, the anterior approach with corpectomy may be attempted. Occasionally PMAVFs in uncommon positions require special treatment strategies. For example, Giese et al reported a case of thoracic PMAVF in which the transmedullary approach was used. In this case, a standard dorsal approach to fistula occlusion is taken via the gliotic channel of the transmedullary drainage vein. Such an approach can be a useful alternative (65).

Apart from the routine surgical removal of PMAVFs, other rare treatment methods have been described. Witiw et al reported a 62-year-old male with a type A fistula at S2-3 between the distal anterior spinal artery and an early draining vein returning cranially along the filum terminale. By transecting the filum terminale, it was possible to indirectly disrupt the medullary arterial supply to the intradural fistula as well as the outflow to the medullary venous plexus. Selective spinal angiography at 1 year demonstrated no residual arteriovenous shunt (66). This case provides a novel idea for the treatment of this type of disease.

Endovascular embolization. Recently, the rapid development of endovascular embolization materials has permitted access to an increasing number of fistulas fed by small arteries (67). The endovascular approach is usually the first-line treatment in patients with some type B and C PMAVFs because the feeding arteries are generally large enough to allow distal microcatheter placement near the fistula. In spinal cord PMAVFs, the closure of the vein at the fistula site is critical for successful endovascular treatment (68). For large high-flow fistulas, the use of a coil is more appropriate because it is more stable than glue and cannot easily be washed away (69). Pasqualetto et al used a coil to treat a boy with a type $C$ high-flow PMAVF, and a good outcome was achieved (70). In addition, Batista et al used coils to embolize two high-flow PMAVFs that were fed by the posterior spinal artery and good outcomes were achieved (71). Therefore, the use of a coil may offer a safe and effective strategy in some high-flow PMAVFs.

In addition to coils, Onyx glue is also a good choice, especially when the microcatheter used to deliver these coils cannot easily access the PMAVF. However, the softer marathon catheter can access the PMAVF more easily to deliver Onyx glue. For example, in their 2012 study, Lv et al used Onyx to treat four spinal cord PMAVFs and achieved good results in all cases (72). In some cases, the combination of Onyx and a coil was beneficial. In 2013, Honarmand et al reported 2 cases that were treated with Onyx. In the 1 case, Onyx glue was used after coil embolization, and in the other case, only Onyx glue was used; in both cases, the outcomes were good (73). However, complications from embolization with Onyx may arise due to inadvertent embolization or embolic reflux into anterior and posterior end artery supply to the spinal cord. In addition, due to the angiotoxicity of dimethyl sulfoxide (DMSO), there is a potential risk of developing perimedullary phlebitis and severe vasospasms. Therefore, extra care should be taken when Onyx glue is used.

In a study by Hsiao et al, the case of a 51-year-old female with lower-thorax PMAVF was reported. Onyx was first used for embolization treatment, and the initial outcome was satisfactory. However, 2 months later, the symptoms returned to baseline level; therefore, the fistulas were removed surgically. Severe adhesions between nerve and occult venous varices were observed intraoperatively. The possibility of Onyx-induced perivascular inflammation, resulting in nerves adhering to one another and to occult venous varices, cannot be excluded (74). Therefore, Onyx glue should be used carefully. Due to these disadvantages of Onyx, some researchers recommend that $n$-butyl-2-cyanoacrylate (NBCA) be used for embolization. In a 2014 study of 20 patients with 21 PMAVFs, Phadke et al used NBCA to successfully treat 16 lesions in 15 patients. These authors suggested that endovascular NBCA glue embolization is safe and efficacious for treating type $\mathrm{B}$ and $\mathrm{C}$ PMAVFs and should be considered the first option for treatment. The use of NBCA is also feasible in many type A lesions (58). A new NBCA product is Glubran, which is also a good choice. For example, in 2007, Ioannidis et al reported the use of Glubran for successful embolization of a giant PMAVF of the cervical spine in a 6-year-old child (75).

Combination of surgical and endovascular treatment. Occasionally, the treatment of PMAVFs is difficult to accomplish using surgery or interventional embolization alone. When PMAVFs are high-flow and large, simple surgical removal is dangerous, and it can be difficult to completely occlude the fistula via endovascular treatment (76). In this case, the two methods may be combined. For example, in the 20-case study 
reported in 1999 by Hida et al, joint surgical and interventional treatment was used in 9 cases of type B and C PMAVFs, and good outcomes were reported. This success was primarily due to preoperative embolization, which notably reduced blood flow via the PMAVFs and facilitated subsequent surgical procedures (34). Recently, hybrid operations have become popular, including the combination of interventional embolization and intraoperative surgical exposure in hybrid operations. For example, Shin et al reported a case in which a woman with PMAVF on the surface of the conus medullaris was combined with AVM. For the PMAVF, this patient was treated via intraoperative direct fistula sac puncture and embolization using NBCA, and a good outcome was achieved (31). In some cases, the percutaneous puncture treatment method can be used directly (77). Casasco et al reported a group of 6 patients with cervical giant PMAVFs, 3 of which underwent arterial embolization, 2 underwent venous embolization, and 1 underwent direct percutaneous puncture of the venous pouch. The treatment outcomes were satisfactory (78).

\section{Therapeutic outcome of spinal cord PMAVFs}

Most PMAVFs can have satisfactory outcomes after appropriate surgical or endovascular treatments. For instance, Gross and Du collected information on 213 patients from 28 studies and found that the surgical obliteration rate was $88 \%$; $68 \%$ of these patients improved, $26 \%$ showed no change in condition, and the condition worsened in $6 \%$. The endovascular obliteration rate was $74 \%$; of these patients, $75 \%$ improved, $14 \%$ showed no change and $11 \%$ worsened (9). In addition, the treatment of pediatric cases can also achieve good outcomes. Meng et al studied 19 child PMAVF cases in 2010, and in this limited study, the treatment outcomes were satisfactory. Of the 14 children who were followed-up, $42.9 \%(6 / 14)$ were succefully treated and 7 (50\%) had greatly improved (79). Cervical PMAVFs can also achieve good therapeutic outcomes, as identified by Endo et al. In that study, 20 of 22 patients were rated as having a good recovery 6 months after surgery (20).

The therapeutic results with PMAVFs also depend on the classification, with type C PMAVFs having the best outcomes. This difference is primarily due to patients with types A or B PMAVFs typically having a long disease history. By the time of treatment, most of these patients have already developed secondary spinal cord injuries, such as spinal cord edema. Despite the embolization of PMAVFs or removal of the fistula, secondary spinal cord injuries typically result in difficult recoveries, and the outcome is often poor. Although type C PMAVFs have high flow, an acute onset and severe symptoms at onset, they do not cause severe secondary spinal cord injuries; therefore, the prognosis for this type is better. Of the 32 cases reported by Antonietti et al in 2010, the treatment outcomes for type $\mathrm{C}$ fistulas showed greater improvement (62\%) than for types A and B fistulas (26 and 27\%) (21). In a 1993 study, 35 cases were described by Mourier et al and complete occlusion of the PMAVFs was achieved in patients with type A and B fistulas. Despite this success, improvement in symptoms was noted in only $50 \%$ of these patients compared with improvement in $100 \%$ of patients with type C fistulas (25). In addition, type C fistulas, shunt lesions with high-velocity drainage, are more comparable to intramedullary AVMs and show a more reliable response to treatment. Thus, the therapeutic outcome for type III or C is optimal.

\section{Complications of spinal cord PMAVF treatment}

Vascular rupture and formation of a reverse thrombosis. Vascular rupture is the most severe potential complication of PMAVF treatment. In a 32-case study reported in 2010 by Antonietti et al, one feeding artery rupture occurred during endovascular therapy. The bleeding caused by the rupture compressed the spinal cord and exacerbated the symptoms. After the blood was absorbed, the symptoms were gradually relieved (21). Occasionally, postsurgical retrograde thrombosis of the anterior spinal artery can occur. Anticoagulation has been used in a few cases that were associated with severe congestion of the pial venous plexuses along the spinal cord; such patients are usually managed by elevating the head of the bed to allow gravity to assist in decreasing the intradural venous pressure (21).

Residual fistula. A residual fistula may cause a lack of symptomatic improvement. In the 32-case study reported in 2010 by Antonietti et al residual shunting was noted in 6 patients. The presence of a residual fistula on follow-up angiography was associated with progressive worsening or lack of improvement in neurologic function (21). In an earlier example from the 20-case study reported in 1999 by Hida et al, residual fistulas were found in 4 patients, and postoperative neurological status was unchanged (34). Occasionally, when the residual fistula is small, the symptoms may improve. For example, in a study of 20 patients with 21 PMAVFs reported by Phadke et al, NBCA was used to successfully treat 16 lesions in 15 patients. There were 3 cases with small residual fistulas, but the symptoms improved (58). However, if the residual fistulas result in a worsening or lack of improvement in neurologic function, retreatment is necessary.

\section{Conclusion}

PMAVFs are rare events with an unclear natural history, and it is suggested that asymptomatic PMAVFs are uncommon. PMAVFs can be classified according to their hemodynamic characteristics, anatomical characteristics and size. The most widely used classification method is the type A-C classification method proposed by Spetzler et al (23). The classification of PMAVFs can inform their treatment and prognosis. The clinical characteristics of PMAVFs are unique. They can occur in all age groups but are most common in children, where they are generally large and exhibit high flow. Most PMAVFs in children begin with bleeding and frequently occur in combination with rare syndromes, such as HHT. PMAVFs can also be found in adults, although these are primarily small and low-flow lesions, and most occur following progressive spinal cord dysfunction. The treatment of PMAVFs is fairly difficult. Interventional embolization or surgical removal treatment can be used or both treatments can be used jointly. Most PMAVFs improve after treatment, and the treatment outcome is primarily associated with the classification of PMAVFs. For types A and B, surgery is most often used to close the fistula, whereas for type C 
high-flow lesions, interventional embolization treatment is most often used. Thus, type $\mathrm{C}$ has the best prognosis.

\section{References}

1. Djindjian M, Djindjian R, Rey A, Hurth M and Houdart R: Intradural extramedullary spinal arterio-venous malformations fed by the anterior spinal artery. Surg Neurol 8: 85-93, 1977.

2. Sure U, Wakat JP, Gatscher S, Becker R, Bien S and Bertalanffy H: Spinal type IV arteriovenous malformations (perimedullary fistulas) in children. Childs Nerv Syst 16: 508-515, 2000.

3. Halbach VV, Higashida RT, Dowd CF, Fraser KW, Edwards MS and Barnwell SL: Treatment of giant intradural (perimedullary) arteriovenous fistulas. Neurosurgery 33: 972-980, 1993.

4. Bai Y,Zhi X, Jian F,Zhang H and Ling F: Traumatic spinal perimedullary arteriovenous fistula due to knife stabbing and subsequent kyphosis: Case report. J Neurosurg Spine 19: 222-225, 2013.

5. Meng X, Zhang H, Chen Y and Ling F: Traumatic spinal perimedullary arteriovenous fistula: A case report. Acta Neurochir (Wien) 152: 1407-1410, 2010

6. Cullen S, Krings T, Ozanne A, Alvarez H, Rodesch G and Lasjaunias P: Diagnosis and endovascular treatment of pediatric spinal arteriovenous shunts. Neuroimaging Clin N Am 17: 207-221, 2007.

7. Matushita H, Caldas JG and Texeira MJ: Perimedullary arteriovenous fistulas in children: Report on six cases. Childs Nerv Syst 28: 253-264, 2012

8. Davagnanam I, Toma AK and Brew S: Spinal arteriovenous shunts in children. Neuroimaging Clin N Am 23: 749-756, 2013.

9. Gross BA and Du R: Spinal pial (type IV) arteriovenous fistulae: A systematic pooled analysis of demographics, hemorrhage risk, and treatment results. Neurosurgery 73: 141-151, 2013.

10. Takai K and Usui M: Spontaneous thrombosis of a spinal conus perimedullary arteriovenous fistula. Case report. Neurol Med Chir (Tokyo) 52: 103-106, 2012.

11. Aydin K, Sencer S, Sencer A, Terzibaşioglu E and Minareci O Angiography-induced closure of perimedullary spinal arteriovenous fistula. Br J Radiol 77: 969-973, 2004.

12. Heros RC, Debrun GM, Ojemann RG, Lasjaunias PL and Naessens PJ: Direct spinal arteriovenous fistula: A new type of spinal AVM. Case report. J Neurosurg 64: 134-139, 1986.

13. Gueguen B, Merland JJ, Riche MC and Rey A: Vascular malformations of the spinal cord: Intrathecal perimedullary arteriovenous fistulas fed by medullary arteries. Neurology 37: 969-979, 1987.

14. Gailloud P, Gregg L, Katz Z, Myseros JS and Pearl MS: Duplicated origin of a radiculomedullary artery supplying a perimedullary arteriovenous fistula: Angiographic observation and developmental considerations. Anat Sci Int 89: 191-194, 2014

15. Cohen JE, Constantini S, Gomori JM, Benifla M and Itshayek E: Pediatric perimedullary arteriovenous fistula of the conus medullaris supplied by the artery of Desproges-Gotteron. J Neurosurg Pediatr 11: 426-430, 2013.

16. Rodesch G, Hurth M, Alvarez H, Tadie M and Lasjaunias P: Spinal cord intradural arteriovenous fistulae: Anatomic, clinical, and therapeutic considerations in a series of 32 consecutive patients seen between 1981 and 2000 with emphasis on endovascular therapy. Neurosurgery 57: 973-983, 2005.

17. Kaloostian PE, Chen H, Khan SH and Taylor C: Brief Report: Concurrent cervical giant perimedullary arteriovenous fistula aneurysm on a feeding artery of fistula and unilateral congenital carotid aplasia. J Vasc Interv Neurol 7: 50-54, 2014

18. Ohmori Y, Hamada J, Morioka M and Yoshida A: Spinal aneurysm arising from the feeding pedicle of a thoracic perimedullary arteriovenous fistula: Case report. Surg Neurol 64: 468-470, 2005.

19. Anderer EG, Kang MM, Moshel YA and Frempong-Boadu A: Successful management of an anterior thoracic type IV spinal arteriovenous malformation with two associated aneurysms utilizing vertebrectomy. Technical note. J Neurosurg Spine 9: 67-70, 2008.

20. Endo T, Shimizu H, Sato K, Niizuma K, Kondo R, Matsumoto Y, Takahashi A and Tominaga T: Cervical perimedullary arteriovenous shunts: A study of 22 consecutive cases with a focus on angioarchitecture and surgical approaches. Neurosurgery 75 : 238-249, 2014

21. Antonietti L, Sheth SA, Halbach VV, Higashida RT, Dowd CF Lawton MT, English JD and Hetts SW: Long-term outcome in the repair of spinal cord perimedullary arteriovenous fistulas. AJNR Am J Neuroradiol 31: 1824-1830, 2010.
22. Merland JJ, Riche MC and Chiras J: Intraspinal extramedullary arteriovenous fistulae draining into the medullary veins. J Neuroradiol 7: 271-320, 1980.

23. Spetzler RF, Detwiler PW, Riina HA and Porter RW: Modified classification of spinal cord vascular lesions. J Neurosurg 96 (Suppl 2): 145-156, 2002

24. Rodesch G, Hurth M, Alvarez H, Tadie M and Lasjaunias P: Classification of spinal cord arteriovenous shunts: Proposal for a reappraisal - the Bicêtre experience with 155 consecutive patients treated between 1981 and 1999. Neurosurgery 51: 374-380, 2002.

25. Mourier KL, Gobin YP, George B, Lot G and Merland JJ: Intradural perimedullary arteriovenous fistulae: Results of surgical and endovascular treatment in a series of 35 cases. Neurosurgery 32: 885-891, 1993.

26. Mont'Alverne F, Musacchio M, Tolentino V, Belzile F, Riquelme C and Tournade A: Giant spinal perimedullary fistula in hereditary haemorrhagic telangiectasia: Diagnosis, endovascular treatment and review of the literature. Neuroradiology 45: 830-836, 2003.

27. Sharma S: Multifocal intradural spinal AVF and renal artery aneurysms in a case of Klippel Trenaunay Syndrome (KTS). J Neuroimaging 20: 386-389, 2010.

28. Niimi Y, Ito U, Tone O, Yoshida K, Sato S and Berenstein A: Multiple spinal perimedullary arteriovenous fistulae associated with the Parkes-Weber syndrome. A case report. Interv Neuroradiol 4: 151-157, 1998

29. Morgalla MH, Ernemann U, Gawlowski J, Deininger M, Bitzer $\mathrm{M}$ and Grote EH: Recurrent spinal fistula as result of a rare combination of a perimedullary and peridural spinal fistula: Case report. Surg Neurol 61: 347-352, 2004.

30. Ling JC, Agid R, Nakano S, Souza MP, Reintamm G, Terbrugge KG and Kim TK: Metachronous multiplicity of spinal cord arteriovenous fistula and spinal dural AVF in a patient with hereditary haemorrhagic telangiectasia. Interv Neuroradiol 11: 79-82, 2005.

31. Shin HK, Suh DC and Jeon SR: Intraoperative direct puncture and embolization (IOPE) using a glue material for spinal cord arteriovenous fistula: A case report. Eur Spine J 24 (Suppl 4): S594-S599, 2015.

32. Gekka M, Seki T, Hida K, Osanai T and Houkin K: Surgical management of combined intramedullary arteriovenous malformation and perimedullary arteriovenous fistula within the hybrid operating room after five years of performing focus fractionated radiotherapy: Case report. Neurol Med Chir (Tokyo) 54: 936-940, 2014.

33. Zozulya YP, Slin'ko EI and Al-Qashqish II: Spinal arteriovenous malformations: New classification and surgical treatment. Neurosurg Focus 20: E7, 2006.

34. Hida K, Iwasaki Y, Goto K, Miyasaka K and Abe H: Results of the surgical treatment of perimedullary arteriovenous fistulas with special reference to embolization. J Neurosurg 90 (Suppl 2): 198-205, 1999.

35. Ding D, Law AJ, Scotter J and Brew S: Lumbar disc herniation exacerbating venous hypertension from a spinal perimedullary arteriovenous fistula of the filum terminale. J Neurol Sci 369: 276-277, 2016.

36. Ricolfi F, Gobin PY, Aymard A, Brunelle F, Gaston A and Merland JJ: Giant perimedullary arteriovenous fistulas of the spine: Clinical and radiologic features and endovascular treatment. AJNR Am J Neuroradiol 18: 677-687, 1997.

37. Sasamori T, Hida K, Yano S, Asano T and Iwasaki Y: Cervical perimedullary arteriovenous fistula in an infant presenting with subarachnoid hemorrhage - case report. Neurol Med Chir (Tokyo) 48: 409-413, 2008

38. Kenning TJ, Deshaies EM, Adamo MA, Waldman JB and Boulos AS: Onyx embolization of a thoracolumbar perimedullary spinal arteriovenous fistula in an infant presenting with subarachnoid and intraventricular hemorrhage. J Neurosurg Pediatr 3: 211-214, 2009.

39. Vates GE, Quiñones-Hinojosa A, Halbach VV and Lawton MT: Conus perimedullary arteriovenous fistula with intracranial drainage: Case report. Neurosurgery 49: 457-461, 2001.

40. Cullen S, Alvarez H, Rodesch G and Lasjaunias P: Spinal arteriovenous shunts presenting before 2 years of age: Analysis of 13 cases. Childs Nerv Syst 22: 1103-1110, 2006.

41. Stephan MJ, Nesbit GM, Behrens ML, Whitaker MA, Barnwell SL and Selden NR: Endovascular treatment of spinal arteriovenous fistula in a young child with hereditary hemorrhagic telangiectasia. Case report. J Neurosurg 103 (Suppl 5): 462-465, 2005.

42. Saito A, Takahashi T, Ezura M and Tominaga T: Intercostal arteriovenous fistula associated with neurofibromatosis manifesting as congestive myelopathy: Case report. Neurosurgery 61: E656-E657, 2007. 
43. Vitarbo EA, Sultan A, Wang D, Morcos JJ and Levi AD: Split cord malformation with associated type IV spinal cord perimedullary arteriovenous fistula. Case report. J Neurosurg Spine 3: 400-404, 2005.

44. Hung KC and Chiang YH: Spinal arteriovenous fistulae with a concomitant cauda equina schwannoma. Spine J 8: 391-393, 2008

45. Rosenow J, Rawanduzy A, Weitzner I Jr and Couldwell WT: Type IV spinal arteriovenous malformation in association with familial pulmonary vascular malformations: Case report. Neurosurgery 46: 1240-1244, 2000.

46. Yang HK, Lee JW, Jo SE, Jung C, Kwon OK, Lee E, Ahn JM and Kang HS: MRI findings of spinal arteriovenous fistulas: Focusing on localisation of fistulas and differentiation between spinal dural and perimedullary arteriovenous fistulas. Clin Radiol 71: 381-388, 2016.

47. Condette-Auliac S, Boulin A, Roccatagliata L, Coskun O, Guieu S, Guedin P and Rodesch G: MRI and MRA of spinal cord arteriovenous shunts. J Magn Reson Imaging 40: 1253-1266, 2014

48. Unsrisong K, Taphey S and Oranratanachai K: Spinal arteriovenous shunts: Accuracy of shunt detection, localization, and subtype discrimination using spinal magnetic resonance angiography and manual contrast injection using a syringe. J Neurosurg Spine 24: 664-670, 2016.

49. Toossi S, Josephson SA, Hetts SW, Chin CT, Kralik S, Jun P and Douglas VC: Utility of MRI in spinal arteriovenous fistula. Neurology 79: 25-30, 2012.

50. Hasegawa M, Fujisawa H, Kawamura T, Yamashita J and Matsui O: The efficacy of CT arteriography for spinal arteriovenous fistula surgery: Technical note. Neuroradiology 41 915-919, 1999.

51. Yamaguchi S, Eguchi K, Kiura Y, Takeda M, Nagayama T, Uchida H, Ito Y, Hotta T, Arita K and Kurisu K: Multi-detector-row CT angiography as a preoperative evaluation for spinal arteriovenous fistulae. Neurosurg Rev 30: 321-327, 2007.

52. Yamaguchi S, Takeda M, Mitsuhara T, Kajihara S, Mukada K, Eguchi K, Kajihara Y, Takemoto K, Sugiyama K and Kurisu K Application of 4D-CTA using 320-row area detector computed tomography on spinal arteriovenous fistulae: Initial experience. Neurosurg Rev 36: 289-296, 2013.

53. Cao JB, Cui LL, Jiang XY, Gao SJ, Sun WG and Xu K: Clinical application and diagnostic value of noninvasive spinal angiography in spinal vascular malformations. J Comput Assist Tomogr 38: 474-479, 2014.

54. Prestigiacomo CJ, Niimi Y, Setton A and Berenstein A: Three-dimensional rotational spinal angiography in the evaluation and treatment of vascular malformations. AJNR Am J Neuroradiol 24: 1429-1435, 2003.

55. Takai K, Kin T, Oyama H, Iijima A, Shojima M, Nishido $H$ and Saito N: The use of 3D computer graphics in the diagnosis and treatment of spinal vascular malformations. J Neurosurg Spine 15: 654-659, 2011.

56. Sorte DE, Obrzut M, Wyse E and Gailloud P: Normal venous phase documented during angiography in patients with spinal vascular malformations: Incidence and clinical implications. AJNR Am J Neuroradiol 37: 565-571, 2016.

57. Cho KT, Lee DY, Chung CK, Han MH and Kim HJ: Treatment of spinal cord perimedullary arteriovenous fistula: Embolization versus surgery. Neurosurgery 56: 232-241, 2005.

58. Phadke RV, Bhattacharyya A, Handique A, Jain K, Kumar A, Singh V, Baruah D, Kumar T, Patwari S and Mohan BM: Endovascular treatment in spinal perimedullary arteriovenous fistula. Interv Neuroradiol 20: 357-367, 2014

59. Miyoshi Y, Yasuhara T, Nishida A, Tokunaga K, Sugiu K and Date I: Effectiveness of intraoperative near-infrared indocyanine green videoangiography in a case with recurrent spinal perimedullary arteriovenous fistula. Clin Neurol Neurosurg 113 239-242, 2011.

60. Horie N, So G, Debata A, Hayashi K, Morikawa M, Suyama K and Nagata I: Intra-arterial indocyanine green angiography in the management of spinal arteriovenous fistulae: Technical case reports. Spine 37: E264-E267, 2012.

61. Seki T, Hida K, Lee J, Yano S and Iwasaki Y: Intraoperative color Doppler sonography in the surgical treatment of perimedullary arteriovenous fistula - case report. Neurol Med Chir (Tokyo) 45 : 100-103, 2005.
62. Trinh VT and Duckworth EA: Surgical excision of filum terminale arteriovenous fistulae after lumbar fusion: Value of indocyanine green and theory on origins (a technical note and report of two cases). Surg Neurol Int 2: 63, 2011.

63. Xia Y, Ishii K, Nakamura M, Onozuka S, Ueda R, Matsumoto M, Chiba K and Toyama Y: The validity of intraoperative angiography for the treatment of spinal arteriovenous fistula. J Spinal Disord Tech 20: 442-448, 2007.

64. Hida K, Iwasaki Y, Ushikoshi S, Fujimoto S, Seki T and Miyasaka K: Corpectomy: A direct approach to perimedullary arteriovenous fistulas of the anterior cervical spinal cord. J Neurosurg 96 (Suppl 2): 157-161, 2002.

65. Giese A, Winkler PA, Schichor C, Kantelhardt SR, Boeckh-Behrens T, Tonn JC and Rohde V: A transmedullary approach to occlusion of a ventral perimedullary arteriovenous fistula of the thoracic spinal cord. Neurosurgery 66: 611-615, 2010.

66. Witiw CD, Fallah A, Radovanovic I and Wallace MC: Sacral intradural arteriovenous fistula treated indirectly by transection of the filum terminale: Technical case report. Neurosurgery 69: E780-E784, 2011.

67. Matsumoto T, Imagama S, Miyachi S, Izumi T, Matsui H, Muramoto A, Tauchi R, Ando K, Ito Z and Ishiguro N: Treatment of perimedullary arteriovenous fistula of the spinal cord by superselective neuroendovascular therapy: A case report and literature review. J Orthop Sci 21: 86-90, 2016.

68. Andersson T, van Dijk JM and Willinsky RA: Venous manifestations of spinal arteriovenous fistulas. Neuroimaging Clin $\mathrm{N}$ Am 13: 73-93, 2003

69. Yamaguchi S, Hamamura T, Ito O, Sayama T, Shimogawa T, Matsukado $\mathrm{K}$ and Morioka T: Thoracocervical giant perimedullary arteriovenous fistula treated with transarterial embolization: A case report. No Shinkei Geka 41: 247-253, 2013 (In Japanese)

70. Pasqualetto L, Papa R, Isalberti M, Nuzzi NP and Branca V: The endovascular treatment of a spinal perimedullary arteriovenous fistula with coils: A case report. J Neurointerv Surg 3: 88-91, 2011.

71. Batista AL, Romero DG, Gentric JC, Weill A, Raymond J and Roy D: Radiculo-pial spinal arteriovenous fistulas treated with coils: Report of two cases. Interv Neuroradiol 21: 527-531, 2015.

72. Lv X, Li Y, Yang X, Jiang C and Wu Z: Endovascular embolization for symptomatic perimedullary AVF and intramedullary AVM: A series and a literature review. Neuroradiology 54: 349-359, 2012

73. Honarmand AR, Ansari SA, Soltanolkotabi M, Tomita T, Alden TD, Hurley MC, Schoeneman SE and Shaibani A: Use of Onyx for endovascular embolization of pediatric spinal perimedullary (type IV) fistula: Case report. Clin Neurol Neurosurg 115: 2260-2263, 2013

74. Hsiao IH, Lee HC, Yen PS and Cho DY: Embolization followed by surgery for treatment of perimedullary arteriovenous fistula causing acute myelopathy. Surg Neurol Int 6 (Suppl 7): S275-S278, 2015

75. Ioannidis I, Sfakianos G, Nasis N, Prodromou P and Andreou A: Successful embolization of a giant perimedullary arteriovenous fistula of the cervical spine in a 6-year-old child. Childs Nerv Syst 23: 1327-1330, 2007.

76. Nagashima C, Miyoshi A, Nagashima R, Ogawa M, Enomoto K and Watabe T: Spinal giant intradural perimedullary arteriovenous fistula: Clinical and neuroradiological study in one case with review of literature. Surg Neurol 45: 524-531, 1996.

77. Casasco A, Guimaraens L, Cuellar H, Theron J and Heredero J: Direct percutaneous venous puncture and embolization of giant perimedullary arteriovenous fistulas. AJNR Am J Neuroradiol 32: E10-E13, 2011.

78. Casasco A, Guimaraens L, Senturk C, Cotroneo E, Gigli R and Theron J: Endovascular treatment of cervical giant perimedullary arteriovenous fistulas. Neurosurgery 70: 141-149, 2012.

79. Meng X, Zhang H, Wang Y, Ye M, He C, Du J and Ling F: Perimedullary arteriovenous fistulas in pediatric patients: Clinical, angiographical, and therapeutic experiences in a series of 19 cases. Childs Nerv Syst 26: 889-896, 2010. 